\title{
Distribution of joint mobility in a normal population: results of the use of fixed torque measuring devices
}

\author{
ALAN J SILMAN, ${ }^{1}$ DORIAN HASKARD,${ }^{2 *}$ AND SIMON DAY \\ From the ${ }^{1}$ Department of Epidemiology and the ${ }^{2}$ Bone and Joint Research Unit, The London Hospital \\ Medical College
}

SUMMARY Fixed torque measuring devices were used to measure the range of movement at three sites in 364 normal adolescents and young adults. The results confirm the findings of less reproducible measurement techniques that joint mobility at a particular site follows a Gaussian distribution with a wide range in a normal population. In addition, apart from very few individuals, mobility at one site could not predict mobility elsewhere. It seems likely that the degree of connective tissue laxity generally is of lesser importance than local factors in determining the range of joint mobility at a given site in normal individuals.

Key words: hypermobility syndrome.

The identification of individuals with the hypermobility syndrome ${ }^{1}$ does not necessarily imply that the latter is a discrete clinical entity rather than the extreme of a distribution. ${ }^{2}$ The widespread use of the Beighton and Horan extension ${ }^{3}$ of Carter and Wilkinson's clinical scoring system,${ }^{4}$ however, has led others to conclude that such a system can clearly distinguish hypermobile individuals. ${ }^{5} \mathrm{~A}$ recent survey of adolescents ${ }^{6}$ observed that in a normal population joint mobility followed a Gaussian shaped continuum with no obvious cut off point. This survey also highlighted the weak correlation within individuals of mobility at different joints.

Standard techniques for the measurement of joint mobility have been criticised for their lack of reproducibility, which can be overcome by the use of a fixed torque apparatus. ${ }^{7}$ The original description was a validation of a device to measure index finger hyperextension, ${ }^{7}$ and we have recently modified this method to measure both forearm and lower limb rotation. ${ }^{8}$ In this report results from the use of these fixed torque devices on a normal adolescent population are presented both in terms of the shape of the distributions observed and the relationship within individuals of mobility at the three sites measured.

Accepted for publication 24 June 1985.

Correspondence to Dr A J Silman, Department of Epidemiology, The London Hospital Medical College.

*Present address: Department of Rheumatology, University of Texas, Dallas, USA.

\section{Patients and methods}

The study population consisted of 364 individuals gathered from a local mixed secondary school and from the biological sciences departments of two polytechnics. There were 266 males and 98 females with an age range of 10 to 24 years. The inclusion of individuals was based solely on their attendance at designated biology classes.

The range of the following joint movements was measured: index finger hyperextension, forearm rotation (total range-pronation plus supination), and lower limb rotation (total range-external plus internal rotation). The techniques used for the fixed torque measurement of these movements and the torques used have been described elsewhere. ${ }^{8}$ All measurements were taken from the subjects' right side to maintain standard conditions. It has previously been described that dominance probably does not affect mobility range. ${ }^{9}$ A single observer was used where possible for each of the three movements measured, though the observers used were not identical for each of the school classes of students measured. In all five observers were used. The interobserver variation for these devices is low, ${ }^{8}$ and thus for analysis the results were pooled from all observers. The constraints of time tabling resulted in some individual subjects not being tested for all three movements. Thus index finger hyperextension was measured in 346 , forearm rotation in 260 , and lower limb rotation in 277 individuals; with 217 of 
these individuals measured with all three devices.

Frequency distributions of the individual values and scattergram plots of the relationship between measurements from the different movements were obtained with SAS. ${ }^{10}$ The relationship between the different movements was further analysed by principle component analysis. Finally, the observed number of individuals in the top $10 \%$ for all three movements was compared with that expected based on no relationship.

\section{Results}

The frequency distributions for the three movements measured were Gaussian or near Gaussian, and the main features of the distributions are summarised in Table 1. All three movements are characterised by a wide variation in this normal $\overrightarrow{\vec{*}}$ population. Only two individuals of the 217 who had measurements at each of the three sites were in the top $10 \%$ in all of the three distributions, but this surprisingly small number was higher than the 0.24 $(p<0.001)$ expected if the distributions were independent. There was no correlation between the three pairs of movements: forearm rotation $v$ leg $\vec{\circ}$ rotation $\mathrm{r}=0 \cdot 183$, index finger hyperextension $v$ leg $\overrightarrow{.}$ rotation $\mathrm{r}=0.019$, index finger hyperextension $v \vec{\omega}$ forearm rotation $r=0 \cdot 004$. This lack of relationship is most clearly shown by examination of the relevant 0 scattergrams (Figs 1-3). Principle component analy- of sis was carried out to determine whether a mobility $\overrightarrow{-}$ score could be obtained for an individual from a v

Table 1 Summary statistics for distribution of range of movement at three sites

\begin{tabular}{|c|c|c|c|c|c|c|}
\hline \multirow[t]{2}{*}{ Movement } & \multirow[t]{2}{*}{$n$} & \multicolumn{5}{|c|}{ Range of movement (degrees) } \\
\hline & & Mean & $S D$ & Range & 5th Centile & 95th Centile \\
\hline Index finger hyperextension & 346 & $62 \cdot 8$ & $14 \cdot 8$ & $20-100$ & 39 & 89 \\
\hline Forearm rotation & 260 & $179 \cdot 1$ & $50 \cdot 6$ & $23-334$ & 84 & 259 \\
\hline Leg rotation & 277 & $75 \cdot 1$ & $42 \cdot 2$ & $5-176$ & 16 & 147 \\
\hline
\end{tabular}

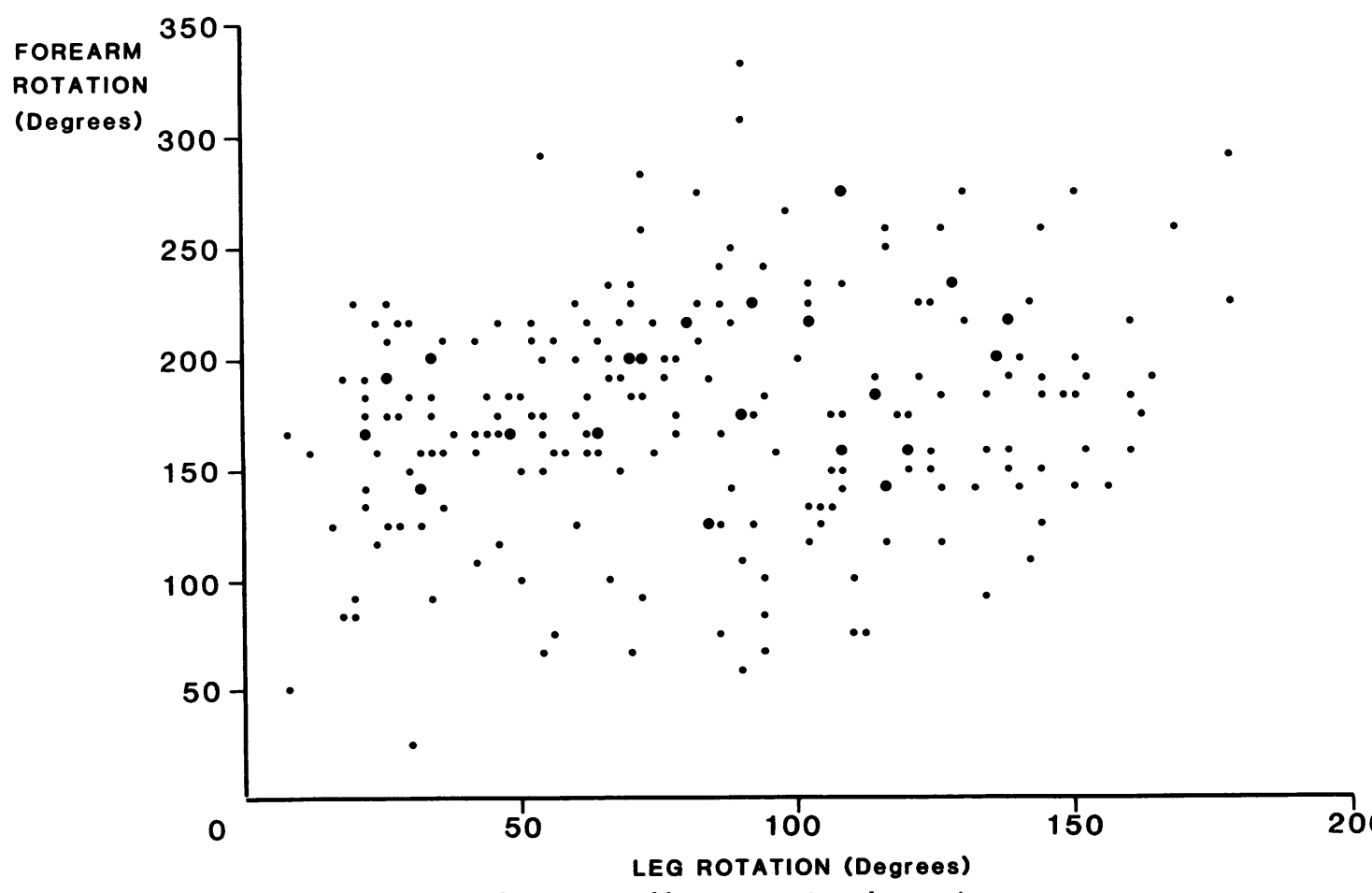

Fig. 1 Scattergram of forearm rotation $\mathrm{v}$ leg rotation. 


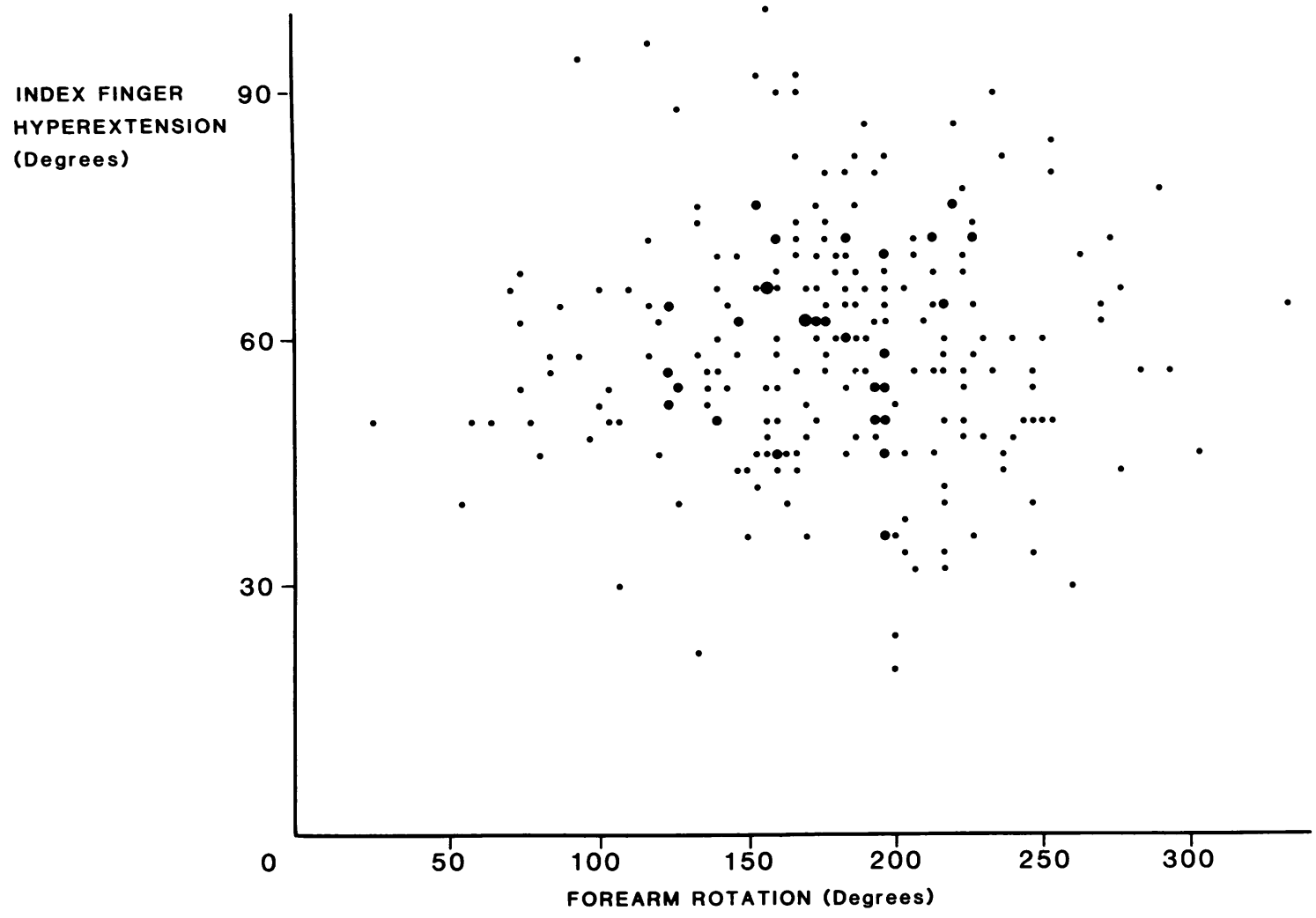

Fig. 2 Scattergram of forearm rotation $\mathrm{v}$ index finger hyperextension.

weighted mean of the mobility for each of the three movements taking into account any inter-relation that existed. The virtual total lack of association between the movements observed meant that the ranking of individuals could not be achieved with any greater precision than the rather unsatisfactory addition of all three results to produce a simple total score.

\section{Discussion}

These results confirm that joint mobility at the sites tested follow a normal distribution and confirm the findings of others based on standard goniometry. ${ }^{6}$ The failure to find any relationship in mobility between the different movements tested was surprising, especially as index finger hyperextension measured in the same way has been shown to correlate with a global score. ${ }^{7}$ However, the study of a similar adolescent population mentioned above ${ }^{6}$ only showed very weak correlations between different joints. The other unexpected but related finding was the very small number of individuals in the top of the distribution for all three movements.

The population studied did not selectively exclude hypermobile individuals insofar as it was expected they should be normally represented in attenders at the classes studied. More worrying is the possibility that the measurement techniques did not validly reflect actual joint mobility. There is no 'gold standard' method with which to compare these results, indeed the data from fixed torque devices are more reproducible than those from standard goniometry. The assumption of measurement validity for the method of study is perhaps supported by three findings. First, the initial validation of these instruments involved the correct classification of clinically known hypermobile individuals. ${ }^{8}$ Secondly, the observed distributions were Gaussian, confirming the observation of others. ${ }^{12} 611$ Thirdly, even the small number of hypermobile individuals observed in this study had significantly higher values than expected.

We conclude therefore that hypermobile individuals for a given movement represent an extreme of a normal distribution. Additionally, mobility at a 


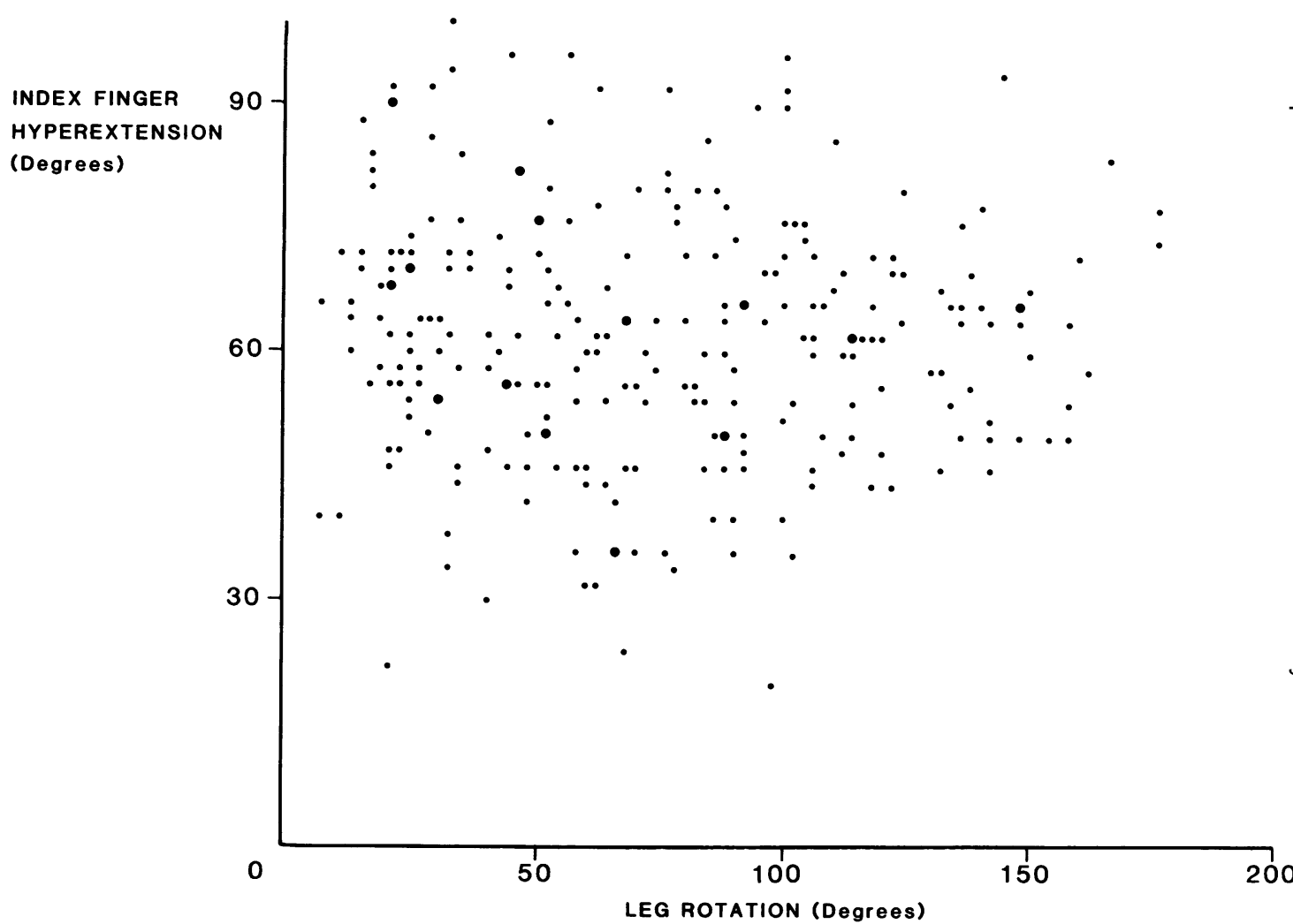

Fig. 3 Scattergram of leg rotation $\mathrm{v}$ index finger hyperextension.

particular site perhaps in part reflects the general degree of tissue laxity, but local factors are more likely to explain the variance between individuals. Global hypermobility appears to be uncommon.

\section{References}

1 Kirk J A, Ansell B M, Bywaters E G L. The hypermobility syndrome: musculoskeletal complaints associated with generalised joint hypermobility. Ann Rheum Dis 1967; 26: 419-25.

2 Wood P H N. Is hypermobility a discrete entity? Proc $R$ Soc Med 1971; 64: 690-2.

3 Beighton P, Solomon L, Soskolne C L. Articular mobility in an African population. Ann Rheum Dis 1973; 32: 413-8.

4 Carter C, Wilkinson, J. Persistent joint laxity and congenital dislocation of the hip. $J$ Bone Joint Surg 1964; 46B: 40-5.
5 Klemp P, Stevens J E, Isaacs S. A hypermobility study in balletion dancers. $J$ Rheumatol 1984; 11: 692-6.

6 Fairbank J C T, Pynsent P B, Phillips H. Quantitative measurement of joint mobility in adolescents. Ann Rheum Dis 1984; 43: 288-94.

7 Jobbins B, Bird H A, Wright V. A joint hyperextensometer for the quantification of joint laxity. Eng Med 1979; 8: 103-4.

8 Haskard D O, Silman A J. Measuring devices for studying jointo mobility in the normal population. Eng Med (in press).

9 Amis A A, Miller J H. The elbow. Clin Rheum Dis 1982; 8: D 571-93.

10 SAS Institute. SAS users guide. Cary: SAS Institute Inc, 1982. N

11 Anonymous. Hypermobile joints [Editorial]. Br Med J 1968; i. 596.

12 Silverman S, Constine L, Harvey W, Graham R. Survey of join mobility and in-vivo skin elasticity in London schoolchildren.W Ann Rheum Dis 1975; 34: 177. 